\title{
O MITO E A RACIONALIDADE CIENTÍFICO-TECNOLÓGICA
}

\author{
MARIA Gabriela Gama*
}

\section{RESUMO}

Procuramos, ainda que de modo sucinto, estabelecer uma relação entre o mito e a racionalidade cientifico-tecnológica.

O mito não é um monopólio do homem primitivo. À medida que a investigação progride, o homem primitivo situa-se cada vez mais perto do homem civilizado, onde emotividade e racionalidade coexistem. A função mitificadora persiste no homem de hoje, para a qual tem contribuído a evolução da ciência e da técnica. Sob a aparência do bem-estar social e do aumento do consumo, para os quais é imprescindível o desenvolvimento científico-tecnológico, justifica-se o controlo totalitário do sistema, onde o homem é o próprio objecto desse mesmo sistema.

Tornando-se num sujeito alienado de uma sociedade de consumo, o homem deixa de se assumir na sua racionalidade crítica e passa a ver-se como um objecto entre os objectos onde ele se vê e se revê nos outros como coisas, cujos comportamentos são estereotipados e unidimensionais.

A ciência e a técnica deram origem a novos mitos na sociedade de consumo. Este modelo de sociedade preconiza uma dupla perspectiva orientada quer para o aumento da produção quer para o consumo. Baudrillard, no livro A Sociedade de Consumo, afirma: "Vivemos a era dos objectos e existimos segundo o seu ritmo e em conformidade com a sua sucessão permanente e vêmo-los nascer, produzir-se e morrer, ao passo que

* Assistente do Departamento de Ciências da Comunicação da Universidade do Minho. E-mail: mgama@ics.uminho.pt 
em civilizações anteriores eram os objectos, instrumentos ou monumentos que sobreviviam às gerações humanas." 1

Sob a aparência de um bem-estar social e de um aumento de consumo, para os quais é imprescindível o desenvolvimento científico-tecnológico, impõe-se o controlo totalitário do sistema, onde o homem é agora o próprio objecto dos mecanismos desse mesmo sistema.

"Em virtude da maneira como está organizada a sua base tecnológica" - refere $H$. Marcuse, na obra $O$ homem unidimensional - "a sociedade industrial contemporânea tende a ser totalitária. Porque não é só «totalitária» uma coordenação política terrorista da sociedade, mas também uma coordenação técnico-económica não-terrorista que opera através da manipulação das necessidades por interesses criados, impedindo portanto o surgimento de uma oposição efectiva contra o todo." 2

A razão tecnológica e científica que tinha a pretensão de dessacralizar o real vai explorar outras formas de sagrado, vai gerar novas mitologias. É da própria racionalidade tecnocrática que irão brotar o mito e as novas formas do sagrado. Nesta linha de pensamento, é inequívoco afirmarmos que, apesar das grandes revoluções científicas e tecnológicas que se vão operando, continuamos a assistir e a vivenciar formas ou modelos míticos de comportamento. Tomemos o exemplo colhido em Roland Barthes, na sua obra Mitologias: "O novo Citroën cai manifestamente do céu, na medida em que se apresenta, antes do mais, como um objecto superlativo. É preciso não esquecer que o objecto é o melhor mensageiro do sobrenatural: há facilmente no objecto, ao mesmo tempo, uma perfeição e uma ausência de origem, um acabamento e um brilho, uma transformação da vida em matéria (a matéria é muito mais mágica que a vida) numa palavra, num silêncio que pertence à ordem do maravilhoso. A Déesse tem todas as características (o público começa pelo menos por atribuir-lhas unanimemente) de um destes objectos vindo de outro universo, que alimentaram a neomania do séc. XVIII e a nossa ficção científica: a Déesse é antes de mais um novo Nautilus." 3

A produção de mitos está generalizada na sociedade de hoje. À semelhança do homem primitivo, o homem contemporâneo transfere para os objectos e imagens as suas aspirações, sejam estas de cariz consciente ou inconsciente. Baudrillard afirma: "(...) é o pensamento mágico que governa o consumo, é uma mentalidade sensível ao miraculoso que rege a vida quotidiana, é a mentalidade primitiva, no sentido em que foi defendida

1 Baudrillard, Jean, A Sociedade de Consumo, Edições 70, Lisboa, 1995, pp. 15-16

2 MARCuSE, Herbert, El hombre unidimensional, Editorial Ariel, Barcelona, 1994, p.33.

3 Barthes, Roland, Mitologias, Círculo de Leitores, s. 1., 1987, p. 164. 
como baseada na crença na omnipotência dos pensamentos: no caso presente, trata-se da crença na omnipotência dos signos da felicidade. (...)

Na prática quotidiana, os benefícios do consumo não se vivem como fruto do trabalho ou de processos de produção; vivem-se como milagres. (...) apesar da abundância se tornar quotidiana e banal, continua a viver-se como milagre diário, na medida em que se revela, não como produzida, arrancada e conquistada, no termo de um esforço histórico e social, mas como dispensada por uma instância mitológica benéfica, de que somos herdeiros legítimos: a Técnica, o Progresso, o Crescimento, etc." 4

Sendo o mito um primeiro esboço de inteligibilização das coisas, é sobretudo uma defesa originada pela angústia e pela incerteza perante a natureza que se apresenta ao homem como múltipla e diversa, inconstante e desordenada. Então, a função do mito é a de ser uma primeira tentativa de unir numa visão global dos acontecimentos desorganizados do mundo.

Face a uma visão desordenada, caótica da natureza, o homem primitivo sentiu necessidade de encontrar uma ordem e um significado. $\mathrm{O}$ mito surge, assim, da necessidade de encontrar uma resposta para o problema do sentido do real. Como nos diz G. Gusdorf na sua obra Mythe et Métaphysique: "A conversão da existência exige a prossecução de um equilíbrio frágil e ameaçado, cuja menor ruptura impõe severas penalidades. Insegurança ontológica, geradora de angústia, como se a própria vida do homem correspondesse a uma transgressão da ordem natural. No seio desta primeira existência, presa do mundo, o mito afirma-se como uma conduta de regresso à ordem. Intervém como protótipo de equilíbrio do universo, como formulário de reintegração." 5

O homem primitivo entendia a realidade como um todo, como um imenso ser vivo, numa solidariedade total e indistinta entre todas as coisas: daqui resulta, como sabemos, o animismo e o antropomorfismo. Além de todas as coisas participarem do todo, participam também do sagrado. $O$ homem de consciência mítica sacralizou a realidade; através do mito ele narra o processo da criação de todas as coisas fazendo intervir a acção decisiva dos deuses.

O sagrado é o divino, o misterioso, mas é também o que provoca o medo e o terror. Como nos diz Mircea Eliade na sua obra $O$ Sagrado $e$ o Profano: "Dizer um mito, é proclamar o que se passou $a b$ origine. Uma vez "dito", quer dizer revelado, o mito torna-se verdade apodíctica: funda a verdade absoluta. (...) O mito proclama a aparição de uma nova «situação» cósmica ou de um acontecimento primordial. Portanto, é sempre a narração de uma "criação»: conta-se como é que qualquer coisa foi efectuada,

4 BAUDRILLARD, Jean, op. cit. pp. 21-23

5 GusDorf, Georges, Mythe et Metaphysique, Flammarion, Paris, 1953, pp. 12-13. 
começou a ser. É por isso que o mito é solidário da ontologia: só fala da realidade, do que aconteceu realmente, do que se manifestou plenamente. (...) É sobretudo este aspecto do mito que convém sublinhar: o mito revela a sacralidade absoluta, porque conta a actividade criadora dos deuses, desvenda a sacralidade das obra deles. Por outros termos, o mito descreve as diversas e por vezes dramáticas irrupções do sagrado no mundo." 6

Mas o mito não surge apenas como uma primeira tentativa de unir numa visão global os acontecimentos desorganizados do mundo, não é apenas uma forma de compreensão, mas é também uma norma de acção. $O$ mito actualiza-se no rito em que o sagrado intervém nos actos do quotidiano, pois só este é capaz de conferir realidade e sentido ao mundo profano.

Todos os actos humanos só têm valor e eficácia se forem repetições das acções originais dos deuses. Os actos sagrados são os únicos que podem conferir sentido e valorizar os gestos, as acções e as normas que regem as relações sociais e que são, deste modo, legitimados através da intervenção do sagrado. Ainda Mircea Eliade na obra Mito do Eterno Retorno: "Um objecto ou uma acção adquirem um valor e, desde modo, tornam-se reais, porque de qualquer forma participam de uma realidade que os transcende. (...)

Em todos os actos do seu comportamento consciente, o "primitivo», o homem arcaico apenas conhece os actos que já foram vividos anteriormente por outro, um outro que não era um homem. Tudo o que ele faz já foi feito. A sua vida é uma repetição ininterrupta de gestos inaugurados por outros.

Esta repetição consciente de gestos paradigmáticos determinados revela uma ontologia original. O produto da natureza ou o objecto fabricado pela indústria só encontram a sua realidade e identidade na medida em que participam numa realidade transcendente.

O gesto só adquire significado, realidade, na medida em que retoma uma acção primordial" 7 .

O mito é uma narrativa real, indiscutível e indubitável e constitui uma verdade absoluta, «apodíctica», uma vez que fala do que realmente aconteceu no tempo original e que deverá servir de modelo aos actos humanos: estes actos só têm valor e eficácia na medida em que são repetições das acções originais dos deuses. Consideremos ainda o que nos diz Mircea Eliade: "Toda a criação brota de uma plenitude. Os deuses criam por um excesso de poder, por um transbordar de energia. A criação faz-se por um acréscimo de substância ontológica. É a razão por que o mito, que conta

6 Elade, Mircea, O Sagrado e o Profano, LBL, Lisboa, s. d., pp. 107-109.

7 Eliade, Mircea, Mito do Eterno Retomo, Ediçōes 70, Lisboa, 1981, pp. 18-19. 
esta ontofania sagrada, esta manifestação vitoriosa de uma plenitude de ser, se torna o modelo exemplar de todas as actividades humanas." 8

Como já referimos, o homem primitivo actua sobre a natureza através de ritos; nestas cerimónias tenta recriar-se o acontecimento original que ocorreu no tempo inicial; além disso, através dos ritos procura-se ainda atrair a simpatia dos deuses sobre o mundo. Por outras palavras, podemos dizer que, paralelamente a uma explicação sobrenatural das coisas, constrói-se todo um ritual imitativo que irá caracterizar um processo de acção mágica. Nos actos mágicos, o homem primitivo imita a realização daquilo que deseja, na crença de que através desse modo é possível obrigar a natureza a fazer o que dela se espera; imitam-se e repetem-se os gestos dos deuses, tornando-se este ritual mimético o garante do sucesso.

$O$ mito narra a maneira como o homem vê o mundo. $O$ real é uma totalidade vivida. $\mathrm{O}$ real não se distingue do subjectivamente vivido nas sensações, nas emoções, na imaginação. Na narração mítica, os elementos explicativos estão intimamente associados aos elementos que resultam da experiência imediata. É uma mentalidade sincrética, isto é, homem e natureza fazem parte de um todo indissociável. $\mathrm{O}$ mundo do homem primitivo é um mundo concreto, cheio de ressonâncias afectivas intrinsecamente dramático uma vez que na realidade chocam entre si forças antagónicas.

No entanto, o mito sendo uma forma de explicação é simultaneamente uma forma de orientação existencial uma vez que estabelece uma estrutura em relação à qual o homem se situa.

Ao desenhar um bisonte com setas espetadas no seu dorso, desenho esse que ornamentava as paredes das cavernas, o homem primitivo acreditava ser possível abater o animal através da posse da imagem. Também no mundo de hoje o automóvel e o telemóvel, por exemplo, são a referência do estatuto social e económico daqueles que o possuem.

O automóvel, o telemóvel tornam-se símbolos do estatuto social daqueles que o possuem não apenas por uma propensão mítica, mas porque o homem é catequisado, conduzido e acirrado por uma sociedade tecnológica cuja dialéctica consiste na produção e consumo cada vez mais acentuados. Os mecanismos de produção e consumo passam a funcionar como processos sub-reptícios de integração e dominação do homem, onde tudo está padronizado, uniformizado segundo as normas comuns características de uma racionalidade tecnológica direccionada para o consumo, para o supérfluo transformado em necessidade.

8 Idem, O Sagrado e o Profano, op. cit., p. 110. 
Vem a propósito a reflexão de Herbert Marcuse na sua obra $O$ homem unidimensional: "Encontramo-nos de novo perante um dos aspectos mais perturbadores de civilização industrial avançada: o carácter racional da sua irracionalidade. A sua produtividade e eficiência, a sua capacidade de incrementar e difundir as comodidades, de converter o supérfluo em necessário, a destruição em construção, o grau em que esta civilização transforma o mundo-objecto em extensão da mente e o corpo do homem torna-se sujeito da noção de alienação. As pessoas reconhecem-se nas suas mercadorias; encontram a sua alma no seu automóvel, no seu aparelho de alta fidelidade, na sua casa, no seu equipamento de cozinha. O mecanismo que une o indivíduo à sociedade mudou, e o controlo social enraizou-se nas novas necessidades que produziu." 9 Desta forma, surge o "homem unidimensional» de que nos fala Marcuse, numa sociedade onde a razão científico-tecnológica direccionada para um consumo cada vez mais desenfreado impera. $O$ homem produtor desta sociedade é, simultaneamente, o seu objecto; a «máquina desejante» de que nos fala Deleuze na obra $O$ AntiÉdipo: "Desfeita a unidade estrutural da máquina, deposta a unidade pessoal e específica do ser vivo, a máquina e o desejo aparecem directamente ligados, a máquina introduz-se no desejo, a máquina é desejante e o desejo, maquinado. Não é o desejo que está no sujeito, mas a máquina que está no desejo - e o sujeito residual está do outro lado, ao lado da máquina, sobre todo o contorno, parasita da máquina, acessório do desejo vértebro-maquinado" 10

O homem, transformado em máquina de consumo, é também controlado e programado tornando-se num sujeito alienado da «máquina desejante" de uma sociedade de consumo onde predominam comportamentos padronizados, uniformizados característicos das sociedades industriais avançadas.

Tudo é produção, tudo é consumo. Segundo Deleuze, “(...) não há esferas ou circuitos relativamente independentes: a produção é imediatamente consumo e registo, o consumo e o registo determinam directamente a produção, mas determinam-na no seio da própria produção. De tal modo que tudo é produção: produção de produções, de acções e de reacções, de distribuições e de pontos de referência; produção de consumos (...). Tudo é produção: os registos são imediatamente consumidos, destruídos, e os consumos directamente reproduzidos." 11

9 Marcuse, Herbert, op. cit., p. 39.

10 Deleuze, Gilles, O Anti-Édipo - Capitalismo e Esquizofrenia, Assírio \& Alvim, Lisboa, 1966. p. 297

11 Deleuze, Gilles, Ibidem, pp. 9-10. 
O sujeito é assim reduzido a um mero objecto, traduzido por uma dialéctica de produção-consumo e consumo-produção, não lhe permitindo assumir-se na sua verdadeira dimensão. Este sujeito passivo, perdido num mundo de coisas em que ele próprio se coisifica, é um ser alienado no universo da produção e consumo.

A sociedade de consumo é efectivamente uma sociedade onde tudo está organizado e controlado. As pseudonecessidades estão estreitamente ligadas à produção e ao consumo onde a fabricação de mitos funciona como elemento estabilizador do indivíduo.

Baudrillard alerta-nos: "Chegámos ao ponto em que o "consumo" invade toda a vida, em que todas as actividades se encadeiam do mesmo modo combinatório, em que o canal das satisfações se encontra previamente traçado, hora a hora, em que o "envolvimento» é total, inteiramente climatizado, organizado, culturalizado." 12

Quando o sujeito se deixa de assumir na sua dimensão crítica torna-se na "máquina desejante" de uma sociedade direccionada para o consumo, olhando o homem como um mero objecto entre outros objectos, onde o mesmo se vê e se revê nos outros como coisas, cujos comportamentos são esteriotipados, unidimensionais.

Cabe ao sujeito recusar-se à «domesticação» e assumir-se como problematizador do real, mesmo sabendo que se arrisca a processos de marginalização. Ocorre-nos, a propósito, citar Sartre: "Estamos sós e sem desculpas. É o que traduzirei dizendo que o homem está condenado a ser livre. Condenado, porque não se criou a si próprio, e no entanto livre, porque, uma vez lançado no mundo, é responsável por tudo quanto fizer".

Em jeito de conclusão, podemos dizer que enquanto o mito tinha para o homem primitivo uma função estruturante, no mundo de hoje, pelo contrário, tem uma função desestruturante. Esta racionalidade tecnocrática reapropria-se de uma certa capacidade de produzir sentido através de novos mitos.

12 Baudrillard, Jean, op. cit. p. 19. 


\section{BIBLIOGRAFIA}

Barthes, Roland, Mitologias, trad. por José-Augusto Seabra, Círculo de Leitores, s. 1., 1987. BaUdrillard, Jean, A Sociedade de Consumo, trad. por Artur Morāo, Edições 70, Lisboa, 1995.

DELEUZE, Gilles, O Anti-Édipo - Capitalismo e Esquizofrenia, trad. por Joana Moraes Varela e Manuel Carrilho, Assírio \& Alvim, Lisboa, 1966.

Eliade, Mircea, Mito do Etemo Retomo, Ediçōes 70, Lisboa, 1981.

Eliade, Mircea, O Sagrado e o Profano, LBL, Lisboa, s. d.

GUSDORF, Georges, Mythe et Métaphysique, Flammarion, Paris, 1953.

MARCuSE, Herbert, El hombre unidimensional, trad. por António Elorza, Editorial Ariel, Barcelona, 1994. 